\title{
Factors associated with child hunger among food insecure households in Bangladesh
}

\author{
Md Ahshanul Haque', Fahmida Dil Farzana', Sabiha Sultana², Mohammad Jyoti Raihan', \\ Ahmed Shafiqur Rahman ${ }^{1}$, Jillian L. Waid ${ }^{3}$, Nuzhat Choudhury ${ }^{1 *}$ and Tahmeed Ahmed ${ }^{1,2}$
}

\begin{abstract}
Background: Hunger is associated with food insecurity at the household level and is considered as a global public health problem with long term adverse consequences on children's health. This study aims to determine the factors associated with child hunger from a nationally representative sample in Bangladesh among food insecure households.

Methods: Data was derived from the Food Security and Nutritional Surveillance Project; 14,712 children aged 6-59 months belonging to food insecure households contributed to the analysis. Information on food security at the household level was collected for 30 days preceding the survey. Descriptive statistics served to illustrate the variables studied and multiple logistic regression analysis was conducted to identify the significant risk factors for child hunger.

Results: Overall $10 \%$ of the children were found to be hungry. After adjusting for seasonality, residence type and education level of household head, the variables - female headed households [OR: $1.87(1.43-2.45) ; p<0.001$, severely food insecure households [OR: 10.5 (1.43-76.6); $p<0.05$ ], households having women with no education [OR: 1.56 (1.27-1.92); $p<0.05$, poorest asset quintile [OR: $1.50(1.11-2.15) ; p<0.05]$ and the amount of rice consumed per household per week [OR: $0.94(0.92-0.96) ; p<0.001]$ were found to be significantly and independently associated with child hunger.

Conclusions: Out of the potential risk factors examined, our study found significant and independent association of five variables with child hunger: sex of the household head, household food insecurity status, educational status of household women and asset index. Despite all sampled household being food insecure, degree of household food insecurity status appeared to be the strongest predictor of child hunger.
\end{abstract}

Keywords: Child hunger, Food insecurity, Bangladesh, Under 5 children

\section{Background}

Food security is a complex development issue which is linked to health and nutrition. Food insecurity is strongly associated with hunger and poverty and is considered as a global public health problem with long term adverse consequences on children's health $[1,2]$. It is a situation which can be described as "limited or

\footnotetext{
* Correspondence: nuzhat@icddrb.org

${ }^{1}$ Nutrition and Clinical Services Division, International Centre for Diarrhoeal Disease Research, Bangladesh, 68, Shaheed Tajuddin Ahmed Sharani, Mohakhali, Dhaka, Bangladesh

Full list of author information is available at the end of the article
}

uncertain availability of nutritionally adequate and safe foods or limited or uncertain ability to acquire acceptable foods in socially acceptable ways" [3]. Adequate food is defined by the World Food Summit as "all people at all times having access to sufficient, safe, nutritious food to maintain a healthy and active life"[4] and the right to adequate food is a universal human right. However, in situations, when someone cannot acquire adequate amount of food even for a short duration is described as 'hunger' [5].

Food insecurity is often rooted in poverty and is of great importance due to its long-term impact on the 
capacity of families, communities and countries for development [6]. The social concept of hunger which is linked to poverty [7] can be described as a product of food insecurity [8]. Hunger in children pertaining to food insecurity, has been found to be associated with detrimental mental and physical outcomes [9]. Bangladesh is a country in the South Asian region, a region which has a higher growth rate of population compared to other parts of the world and hunger is highly prevalent [1]. Of relevance is that two thirds of all people classified as being 'hungry' reside in Asia, with a significant portion chronically lacking access to optimal amount of food [1].

Despite significant economic progress, Bangladesh remains highly food insecure [10-12] with more than 40 million of its people being 'hungry' [13]. Bangladesh has been ranked $73^{\text {rd }}$ out of 104 developing and transitioning countries in the recent Global Hunger Index [14]. Hunger is synonymous to undernutrition [15] and at least 14\% of all Bangladeshi children under five years of age suffers from some manifestation of undernutrition, with $36 \%$ suffering from the chronic form - stunting [11]. Children, focus of this paper, are particularly vulnerable to undernutrition and hunger among all the age groups with one child dying every five seconds from causes related to hunger [16]. Much research has been done in the country to understand issues related to child health and undernutrition, however, little is known about hunger and the factors determining child hunger along with its consequences in the country due to scarcity of pertinent data. A recently concluded large crosssectional study in Bangladesh, the Food Security Nutritional Surveillance Project (FSNSP), which tracked food security status and nutritional condition throughout Bangladesh, has provided unprecedented opportunity for the assessment of hunger associated with household food insecurity and other relevant contributing factors [17].

Thus the objective of this paper has been set to determine the factors associated with child hunger among food insecure households by analyzing data from a nationally representative sample in Bangladesh collected through the FSNSP.

\section{Methods}

\section{Study context}

Data was derived from FSNSP, a surveillance system that operated to track nutrition and food security. FSNSP followed a repeated cross-sectional design for collecting data countrywide at the household level. The data was collected after the two major harvest seasons, the postaman harvest season (January-April) and the post-aus harvest season (September-December) and also during the monsoon season (May-August). The study area, the whole country, was divided into 13 strata consisting of six vulnerable zones (coastal belt, eastern hills, haor region, padma chars, northern chars and the northwest region) and the seven administrative divisions (Dhaka, Chittagong, Rajshahi, Barisal, Khulna, Sylhet and Rangpur) which contain all the upazilas not included in a surveillance zone, correspond to the seven divisions of Bangladesh. A map of FSNSP zones is illustrated in Fig. 1. From each strata, a set number of upazilas were selected with replacement for further sampling based on the number of upazilas in the strata. From each of the surveillance zones, upazilas were selected by rotation into the sampling frame in order to reduce random variation in estimates between rounds, as has been recommended for surveillance systems by the United Nations (UN) and is commonly done in labour participation surveillance [18]. FSNSP's rotational pattern ensures that $50 \%$ of all upazilas in zones are identical between the same season in subsequent years and between two consecutive rounds. In each round, three new upazilas were selected for sampling and the remaining nine upazilas are drawn from past rounds in each surveillance zone. Each selected upazila remains in the system for four rounds of data collection. In the second stage of sample selection, three rural villages or urban mohalla were chosen at random and without replacement from all the villages/mohalla in each selected upazila. There was no stratification of rural and urban areas during the second stage of selection. The third stage of sample selection was done in the field. In each community, 32 households were selected systematically and interviewed. The starting point for interviews in each village was the first eligible house from a randomly assigned approach road (north, south, east, or west) determined by a random number generator. The next and subsequent households for interview were chosen systematically by counting five or ten households from the previously interviewed household (depending on the size of the village) and, in a "zigzag" fashion, selecting households from both sides of the road. In situations where the identified household was not eligible for inclusion or refused participation, the next household that met the inclusion criteria was selected [19]. Sample size was calculated to obtain representative prevalence estimates for indicators of food insecurity and children's and women's undernutrition by surveillance zone. Sample size calculations were based on the estimated prevalence of seven key indicators such as Round-wise estimation of acute childhood malnutrition, child underweight, chronic childhood malnutrition, proportion of women with chronic energy deficiency, proportion of households with food insecurity, proportion of households with "household food deficit", and proportion of households with poor or borderline food consumption patterns. A trial profile is shown as Fig. 2 . The primary respondent was the mother. Data quality was ensured through multiple procedures of review and 


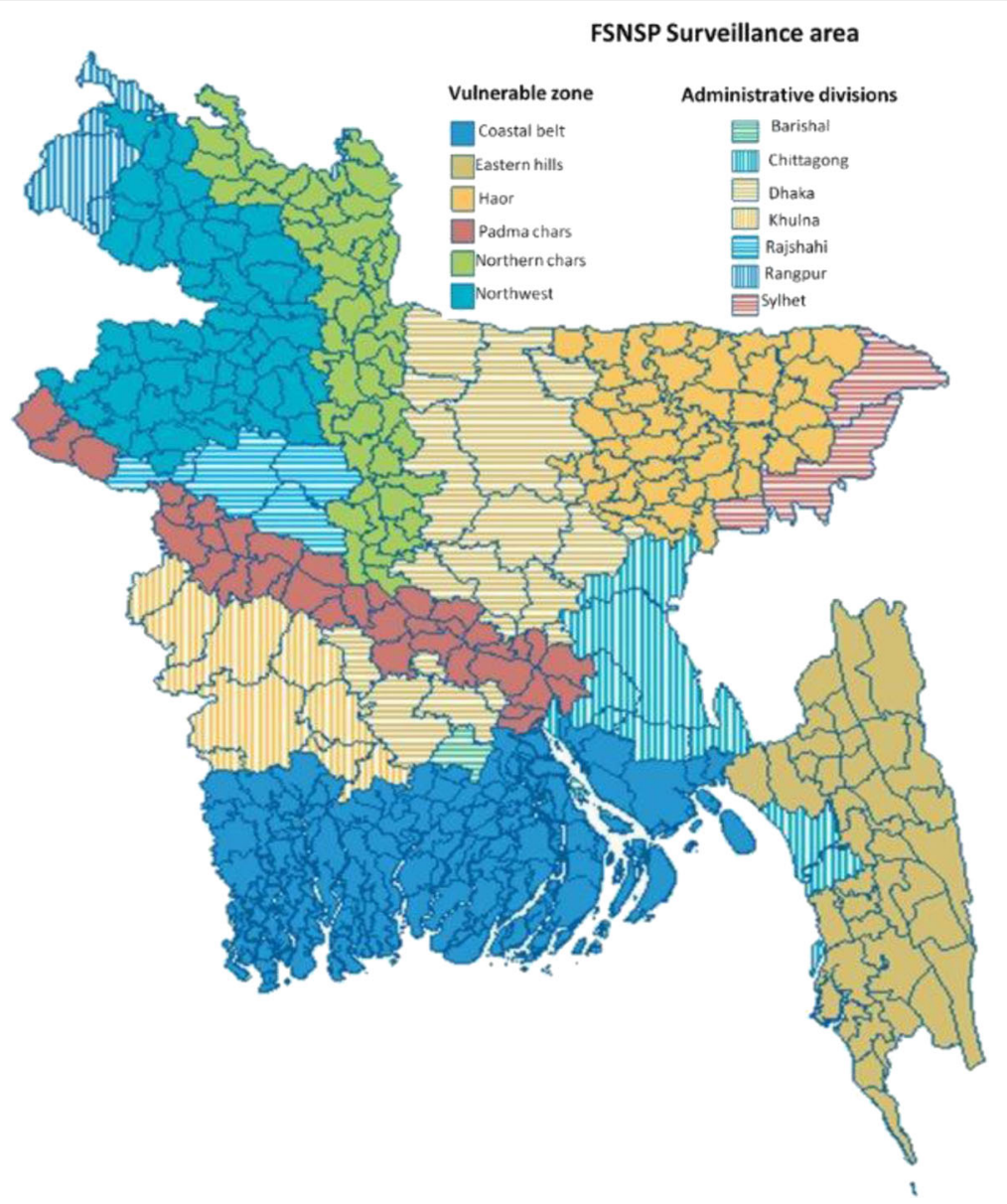

Fig. 1 FSNSP surviellance area

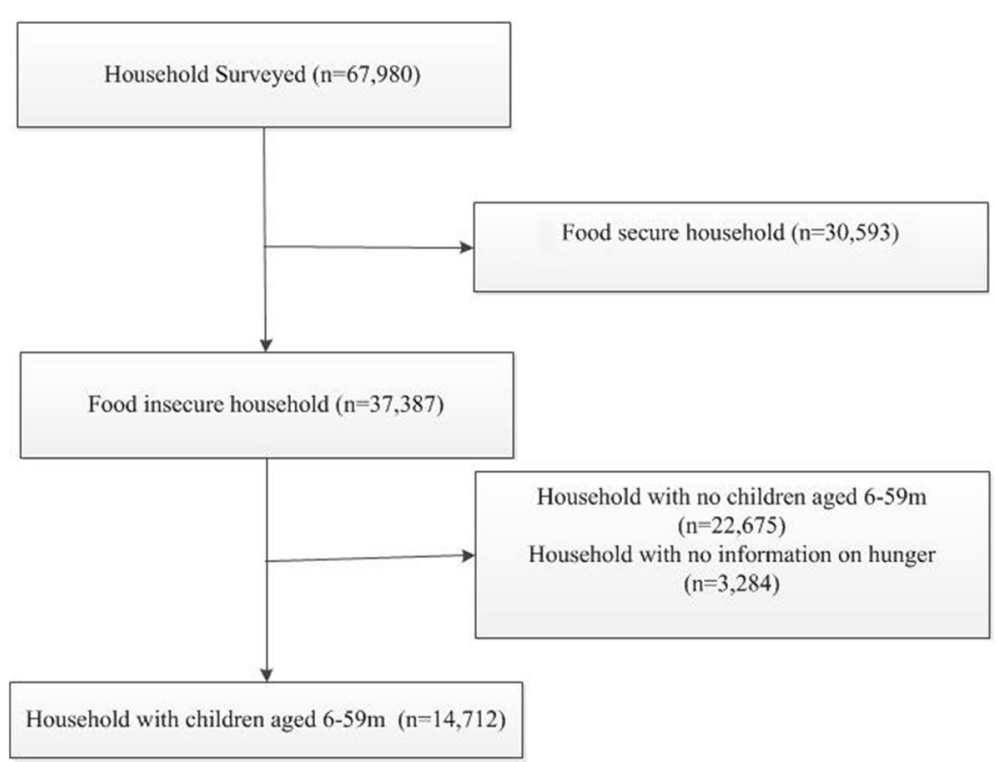

Fig. 2 Trial profile 
cross-checking. Monitoring officers reviewed all questionnaires on the day of completion by the data collectors so that any errors or inconsistencies identified could be corrected in the field. Quality control officers revisited a randomly selected sub-sample (around 10\%) of interviewed households within $48 \mathrm{~h}$ of the initial visit by the data collection team to verify the quality of data collected. For all three rounds conducted in the second field year of FSNSP, internal FSNSP quality control operations were supplemented by Bangladesh Bureau of Statistics (BBS) staff performing a $10 \%$ post-enumeration check using a shortened questionnaire. Quality control data were compared to the surveillance data collected by data collectors. Inconsistencies were reviewed by the project manager, project coordinator, training officer, and field managers to identify possible reasons for the discrepancy and to implement appropriate solutions, such as a review session on selected indicators during the refresher training or a revision of the questionnaire.

Data of 14,712 Bangladeshi children aged 6-59 months belonging to food insecure households as per Household Food Insecurity Access Scale (HFIAS) collected between June 2011 and November 2013 was analyzed for this paper. Information on food insecurity at the household level was collected for the month preceding the survey. FSNSP measures food security through HFIAS which defines food insecurity based on lack of access originated due to poverty rather than shortage of supply [20]. The scale contains 9 questions (Worry about food/unable to eat preferred foods/eat just a few kinds of foods/eat foods they really do not want eat/eat a smaller meal/eat fewer meals in a day/no food of any kind in the household/go to sleep hungry/go a whole day and night without eating) to assess the level of anxiety and uncertainty of the participants about household food supply, insufficient quality of food and insufficient food intake [21]. Data has been collected about child hunger separately in this project so as to determine its relation with food insecurity; to ascertain whether child hunger increases with food insecurity.

\section{Variables of interest}

Child hunger was defined in this study as a household having at least one child who consumed only rice or an amount of food less than required or fewer meals than required or went to bed hungry or a whole day and night without food on the day preceding the survey. The household with such a child was defined as a household having at least one hungry child. Cited literature suggested the selection of variables for this study, the selected variables were seasonality, residence type, sex of household head, educational level of household head, educational status of household women, degree of household food insecurity, amount of rice consumed by the household members and asset index. Seasonality, for this paper, has been defined as the segregation of the year into the post-aman (January-April), monsoon (MayAugust) and post-aus (September-December) periods, type of residence has been dichotomized into rural and urban. Education level of household head has been categorized into 'no formal education', 'below Secondary School Certificate (SSC)' and 'SSC complete and above', educational status of household women was determined on the basis of households having or not having at least one woman, with at least, one year of formal schooling. The asset index used in this study is a composite indicator of household wealth calculated using principal component analysis, following a method similar to that used in the Bangladesh Demographic and Health Survey (BDHS) [11, 22]. The calculation was based on ownership of household electrical appliances, furniture, livestock and vehicles, the type of household construction materials, kitchen fuel and latrine used and the source of drinking water. Food insecurity was categorized as mildly food insecure, moderately food insecure, and severely food insecure.

\section{Statistical analysis}

All analyses were conducted in STATA v10 (StataCorp; College Station, Texas, USA) using the svyset command to adjust strata and cluster for complex survey data. Descriptive statistics served to illustrate the general characteristics and simple logistic regression was used to assess the strength of association (unadjusted) between child hunger and other variables. Multivariate logistic regression analysis was conducted to identify the statistically significant risk factors for child hunger. Logistic regression is the most suitable mode of analysis since the outcome variable is binary and both categorical and continuous variables can be fitted into the regression model. All variables which had $p$-value significant at 0.25 were included in the logistic regression [23]. In the final multiple logistic regression model, variables were considered statistically significant only if the $p$-value was less than 0.05 . Seasonality, residence type, educational status of household head were adjusted in all the steps of the model.

\section{Results}

\section{General characteristics}

Our analysis suggests that 14,712 households were food insecure among which 11,428 households had data on hunger and had at least one child aged 6-59 months. Around 94\% households were from rural area. The average number of household member was five and the average consumption of rice by each household was 13 $\mathrm{kg}$ in the week preceding the survey. Among households who experienced hunger, $81 \%$ were severely food 
insecure. Overall, $10 \%$ of the children were hungry and additionally, around $1 \%$ went a whole day and night (24 h) without eating anything or slept at night being hungry. On the basis of seasonality, the proportion of hungry children was around 8\% during post-aman, 10\% during monsoon and 10\% during post-aus season. Ninety three percent of the households were headed by male and $51 \%$ of the household heads had no formal education. Around 59\% of the primary earner of the households was day laborer, whereas around 16\% households had no women with at least one-year of formal education. All the descriptive findings are tabulated in Table 1.

\section{Strength of association}

Our bivariate and multivariate analyses (Table 2) revealed that seasonality, type of residence as well as education level of household head was not significantly associated with child hunger. The odds of child hunger was 1.87 times [95\% CI: $1.43-2.45 ; p<0.001$ ] in female headed households compared to male headed households. Severe food insecurity in the households appeared to be significantly associated with child hunger [OR: 10.5 (1.43-76.6); $p<0.05$ ] in comparison to mildly food insecure households. It was also found that child hunger was 1.56 times [95\% CI: 1.27-1.92; $p<0.05$ ] more in a household having no educated woman. Odds of a child being hungry in the poorest household was 1.54 times higher [95\% CI: 1.11$2.15 ; p<0.05]$ compared to the richest quintile. The amount of rice consumed by the household members in the past week was negatively associated with child hunger [OR: 0.94 (0.92-0.96); $p<0.001$ ].

\section{Discussion}

Data used in this paper was collected through FSNSP that followed a cross-sectional design with the objective to determine factors which potentially contributes to child hunger among food insecure households. Nearly one tenth children of the current study were found to be hungry. Factors which determined child hunger identified by our study were female household head, severe food insecurity, women with no education, poorest asset quintile and amount of rice consumed per week.

Our multivariate analysis showed that, the odds of child hunger was significantly higher among severely food insecure households which is supported by similar studies [24, 25]. In the FSNSP study, more than three fourth of the households were found to be severely food insecure.

It should also be noted that a significant proportion of the Bangladeshi population remains food insecure despite considerable economic development. Dependency on manual labor and use of traditional techniques with locally available tools in agriculture largely affect crop
Table 1 General characteristics of the subjects

\begin{tabular}{|c|c|}
\hline Variables $(\mathrm{N})$ & n (\%) \\
\hline Amount of rice consumed (9369) mean (SD) & $12.93(6.37)$ \\
\hline \multicolumn{2}{|l|}{ Child hunger (11428) } \\
\hline Overall & $1086(9.51)$ \\
\hline Severe hunger & $109(0.95)$ \\
\hline \multicolumn{2}{|l|}{ Seasonality of child hunger } \\
\hline Post-aman & $210(8.40)$ \\
\hline Monsoon & $428(9.50)$ \\
\hline Post-aus & $448(10.13)$ \\
\hline \multicolumn{2}{|l|}{ Place of residence (14712) } \\
\hline Rural & $13857(94.19)$ \\
\hline Urban & $855(5.81)$ \\
\hline \multicolumn{2}{|l|}{ Sex of the household head (14712) } \\
\hline Male & $13641(92.72)$ \\
\hline Female & $1071(7.28)$ \\
\hline \multicolumn{2}{|l|}{ Education level of household head (14684) } \\
\hline No formal education & $7539(51.34)$ \\
\hline Below secondary school certificate & $6360(43.31)$ \\
\hline Secondary school certificate complete and above & $785(5.35)$ \\
\hline \multicolumn{2}{|l|}{ Occupation of primary earner of the household (9369) } \\
\hline Farmer & $1508(16.10)$ \\
\hline Day laborer & $5558(59.32)$ \\
\hline Businessman & $1233(13.16)$ \\
\hline Professional & $769(8.21)$ \\
\hline Others & $301(3.21)$ \\
\hline \multicolumn{2}{|l|}{ Household food insecurity status (14712) } \\
\hline Mild food insecurity & $1632(11.09)$ \\
\hline Moderate food insecurity & $1172(7.97)$ \\
\hline Severe food insecurity & $11908(80.94)$ \\
\hline \multicolumn{2}{|l|}{ Women education status (14712) } \\
\hline No educated women in the household & $2356(16.01)$ \\
\hline At least one educated women in the household & $12356(83.99)$ \\
\hline \multicolumn{2}{|l|}{ Asset index (14712) } \\
\hline $1^{\text {st }}$ quintile & $3772(25.64)$ \\
\hline $2^{\text {nd }}$ quintile & $3874(26.33)$ \\
\hline $3^{\text {rd }}$ quintile & $3226(21.93)$ \\
\hline $4^{\text {th }}$ quintile & $2145(14.58)$ \\
\hline $5^{\text {th }}$ quintile & $1695(11.52)$ \\
\hline
\end{tabular}

production and influences food availability; as a result, prevalence of food insecurity is high [12, 26].

One of the significant findings of this study, was that female headed households had nearly two-fold risk of having a hungry child. Many factors may contribute to this vulnerability including lower earnings, limited access to assets, land and property and lack of social protection. 
Table 2 Determinants of child hunger

\begin{tabular}{|c|c|c|c|c|c|}
\hline Variables & $n$ & Unadjusted OR (95\%Cl) & $p$-value & Adjusted OR (95\%Cl) & $p$-value \\
\hline Seasonality & 11428 & & & & \\
\hline Post-aus & & Reference & & Reference & \\
\hline Post-aman & & $0.81(0.64-1.03)$ & 0.080 & $1.06(0.82-1.38)$ & 0.638 \\
\hline Monsoon & & $0.93(0.77-1.12)$ & 0.448 & $1.12(0.89-1.40)$ & 0.333 \\
\hline Residence type & 11428 & & & & \\
\hline Urban & & Reference & & Reference & \\
\hline Rural & & $0.99(0.73-1.35)$ & 0.976 & $1.23(0.86-1.75)$ & 0.256 \\
\hline Sex of the household head & 11428 & & & & \\
\hline Male & & Reference & & Reference & \\
\hline Female & & $1.84(1.52-2.23)$ & 0.000 & $1.87(1.43-2.45)$ & 0.000 \\
\hline Education level of household head & 11410 & & & & \\
\hline $\begin{array}{l}\text { Secondary school certificate } \\
\text { complete and above }\end{array}$ & & Reference & & Reference & \\
\hline No formal education & & $1.39(0.94-2.05)$ & 0.097 & $0.91(0.55-1.49)$ & 0.702 \\
\hline Below secondary school certificate & & $1.28(0.86-1.89)$ & 0.220 & $0.93(0.57-1.53)$ & 0.784 \\
\hline Occupation of primary earner of the household & 7290 & & & & \\
\hline Businessman & & Reference & & Reference & \\
\hline Farmer & & $0.98(0.69-1.40)$ & 0.921 & $0.99(0.70-1.41)$ & 0.985 \\
\hline Day laborer & & $1.41(1.10-1.81)$ & 0.007 & $1.22(0.95-1.56)$ & 0.122 \\
\hline Professional & & $1.08(0.71-1.65)$ & 0.722 & $0.97(0.62-1.51)$ & 0.876 \\
\hline Others & & $2.26(1.44-3.55)$ & 0.000 & $1.29(0.80-2.09)$ & 0.293 \\
\hline Household food insecurity access scale & 11428 & & & & \\
\hline Mildly food insecure & & Reference & & Reference & \\
\hline Moderately food insecure & & $0.96(0.43-2.14)$ & 0.924 & $5.07(0.67-38.6)$ & 0.116 \\
\hline Severely food insecure & & $2.19(1.06-4.49)$ & 0.033 & $10.5(1.43-76.6)$ & 0.021 \\
\hline Women education status & 11428 & & & & \\
\hline $\begin{array}{l}\text { At least one educated women in } \\
\text { the household }\end{array}$ & & Reference & & Reference & \\
\hline $\begin{array}{l}\text { No educated women in the } \\
\text { household }\end{array}$ & & $1.60(1.36-1.88)$ & 0.000 & $1.56(1.27-1.92)$ & 0.000 \\
\hline Asset index & 11428 & & & & \\
\hline $5^{\text {th }}$ quintile & & Reference & & Reference & \\
\hline $1^{\text {st }}$ quintile & & $2.09(1.54-2.85)$ & 0.000 & $1.54(1.11-2.15)$ & 0.011 \\
\hline $2^{\text {nd }}$ quintile & & $1.79(1.33-2.41)$ & 0.000 & $1.31(0.94-1.83)$ & 0.111 \\
\hline $3^{\text {rd }}$ quintile & & $1.44(1.05-1.98)$ & 0.024 & $1.09(0.76-1.57)$ & 0.633 \\
\hline $4^{\text {th }}$ quintile & & $1.08(0.76-1.54)$ & 0.653 & $0.91(0.59-1.40)$ & 0.654 \\
\hline Amount of rice consumed & 7290 & $0.93(0.91-0.95)$ & 0.000 & $0.94(0.92-0.96)$ & 0.000 \\
\hline
\end{tabular}

Women were also more likely to be deprived in many other important areas of well-being, such as education, which our study has also found to be correlated with child hunger. In a study done in Southern Ethiopia, increased maternal education was also found to be associated with lower food insecurity and hunger [27]. It is likely that educated females are better equipped, be financially independent, have more control or influence on household resource allocation which lead to a lowering of financial and ultimately, of food insecurity and also ensures better nutrition for children [28, 29]. Educated women additionally, may be, more skillful in domestic financial management. Evidence also suggests that educated mothers are more capable of coping with the many unwritten restrictions and obstacles present in a male dominated society [30]. Factors pertaining to improved child nutrition such as birth spacing and having fewer children are also associated with the education 
status of the mother [31, 32]. In line with our study, established association between household asset index and hunger is seen in published literature [33-35]. The poorest segments of society are in general often most vulnerable to serious economic crisis leading to worsening food and nutrition security at the household level [36]. The world's extremely poor are distributed unevenly across regions and countries. The majority of people living on less than $\$ 1.25$ a day reside in two regions-Southern Asia and sub-Saharan Africa accounting for about $80 \%$ of the extremely poor globally. According to an estimation made in 2011, about $60 \%$ of the world's extremely poor people lives in just five countries, one of which is Bangladesh [37]. All of these factors may contribute towards greater stability and security regarding food.

Economic growth is necessary, but not sufficient for sustaining progress made in the reduction of poverty and hunger. Approximately three-quarters of the world's poor live in rural areas, making up a high percentage of the hungry and malnourished in developing countries $[38,39]$. The same is true for Bangladesh. Thus inclusive growth which enables rural poor to diversify livelihood, is critical to reduce hunger. Lack of purchasing power and ultimately, the lack of access to food, especially for the rural ultra-poor people compel them to remain food insecure. Additionally, adequate food availability at the household level does not necessarily imply that all members of a household enjoy access to enough food. In particular, women and children often suffer from inequalities in intra-household food distribution [40].

Efforts to promote growth in agriculture and the rural sector can be an important component for promoting food security [38]. Another strategy that may be considered is fostering social protection systems efficiently as it directly contributes to the reduction of poverty, hunger and undernutrition by promoting income especially among women [39]. Lastly, as our findings dictate, since educational status of household women is significantly associated with child hunger, emphasis should be given towards women education. The results of this study confirms the significant contribution of relevant sociodemographic and other characteristics towards child hunger among food insecure households.

\section{Limitations and strength}

While the explanatory variables indicate risk factors for child hunger, causal inferences cannot be established due to the cross-sectional nature of the data. A possibility of recall bias remains regarding HFIAS data, as information of 1 month preceding the survey was gathered through maternal response. While, the strength lies in the large sample size and adjustment of seasonality along with separate measurements for food insecurity and hunger. Nevertheless, the present work contributes greatly to our understanding of the socio-economic characteristics related to child hunger among food insecure households.

\section{Conclusions}

As conclusive remarks, it could be said that out of the potential risk factors examined, our study found significant and independent association of five variables with child hunger: sex of household head, primary earner of household, household food insecurity status, educational status of household women and asset index. Degree of household food insecurity status appeared to be the strongest predictor for child hunger among food insecure households. Infants and young children belonging to severe food insecure households are especially at higher risk of being hungry. Efforts directed towards achieving food security are unlikely to be successful if the issue of child hunger is ignored. This paper has tried to shed light on the factors at the food insecure households that compel all member including children to face hunger. This can serve as a result base on which further studies can be conducted to gain more in-depth information about child hunger and relevant areas.

\section{Additional file}

\section{Additional file 1: Food Security and Nutrition Surveillance Data. This data set is a minimal one from a large data set of surveillance on food security and nutrition. It contains unique identification number, region, seasonality, sociodemographic characteristics, food security status and information on child hunger. (DTA 2080 kb)}

\section{Abbreviations}

BDHS: Bangladesh Demographic and Health Survey; BU: BRAC University; EU: European Union; FSNSP: Food Security Nutritional Surveillance Project; HFIAS: Household Food Insecurity Access Scale; icddr,b: International Centre for Diarrhoeal Disease Research, Bangladesh

\section{Acknowledgement}

This research study is funded by James P Grant School of Public Health (JPGSPH), BRAC University (BU). The project FSNSP itself is a joint partnership among JPGSPH, BU, Bangladesh Bureau of Statistics and Helen Keller International, Bangladesh and funded by EU. icddr,b acknowledges with gratitude the commitment of JPGSPH to its research efforts. icddr,b is also grateful to the Governments of Bangladesh, Canada, Sweden and the UK for providing core/unrestricted support.

Funding

The study was funded by James P Grant School of Public Health, BRAC University; Dhaka, Bangladesh.

Availability of data and materials

Dataset has been uploaded as Additional file 1 (Data_FSNSP_dta).

Authors' contribution

TA, NC, FDF and MAH conceptualized the manuscript. FDF, MAH and MJR have performed statistical analysis. FDF, MJR, NC and MAH drafted the manuscript. TA, SS, JLW and ASR contributed to the revision of the final draft for submission. All authors are responsible for the final content of this manuscript. All authors have read and approved the final version. 


\section{Competing interest}

The authors have declared that no competing interest exists.

\section{Consent for publication}

Not applicable.

\section{Ethics approval and consent to participate}

This study (PR-14092) was approved by the Research Review Committee and Ethical Review Committee, the two obligatory components of the institutional review board of International Centre for Diarrhoeal Disease Research, Bangladesh (icddr,b). Verbal informed consent was taken from study participants. Verbal informed consent was taken rather than written because of the cultural stigma about signing papers among rural people of Bangladesh in particular. The enumerators informed the respondent about the purpose of surveillance at the beginning of each interview through reading a consent statement. Verbal consent from the caretaker was also taken regarding anthropometric measurement of the study child. The respondents were informed about the important point that their participation is voluntary and they are also allowed to withdraw themselves at any point of time during the interview.

\section{Author details}

'Nutrition and Clinical Services Division, International Centre for Diarrhoeal Disease Research, Bangladesh, 68, Shaheed Tajuddin Ahmed Sharani, Mohakhali, Dhaka, Bangladesh. ${ }^{2}$ James P Grant School of Public Health, BRAC University, Dhaka 1212, Bangladesh. ${ }^{3}$ Helen Keller International, Dhaka 1212, Bangladesh.

\section{Received: 15 June 2016 Accepted: 4 February 2017} Published online: 16 February 2017

\section{References}

1. Food and Agriculture Organization of the United Nations (FAO), International Fund for Agricultural Development (IFAD), and World Food Programme (WFP). The State of Food Insecurity in the World 2014. Strengthening the enabling environment for food security and nutrition. Rome: FAO; 2014.

2. Kirkpatrick SI, Mclntyre L, Potestio ML. Child hunger and long-term adverse consequences for health. Arch Pediatr Adolesc Med. 2010;164(8):754-62.

3. Anderson SA. Core indicators of nutritional state for difficult-to-sample populations. J Nutr. 1990;120(11):1557-99.

4. Pinstrup-Andersen P. Food security: definition and measurement. Food Sec. 2009;1 (1):5-7.

5. Scott RI, Wehler CA. Food insecurity/food insufficiency: An empirical examination of alternative measures of food problems in impoverished US households. New York: University of Wisconsin-Madison, Institute for Research on Poverty; 1998.

6. World Health Organization. Food Security. In: Trade, foreign policy, diplomacy, Health. 2014.

7. Carlson SJ, Andrews MS, Bickel GW. Measuring food insecurity and hunger in the United States: development of a national benchmark measure and prevalence estimates. J Nutr. 1999;129(2):510S-6S.

8. Bhattacharya J, Currie J, Haider S. Poverty, food insecurity, and nutritional outcomes in children and adults. J Health Econ. 2004;23(4):839-62.

9. Weinreb $L$, et al. Hunger: its impact on children's health and mental health. Pediatrics. 2002;110(4)::41.

10. Malik K. Human development report 2014. Sustaining human progress: Reducing vulnerabilities and building resilience. New York: United Nations Development Programme; 2014.

11. NIPORT, Mitra and Associates, ICF International. Bangladesh Demographic and Health Survey 2014. Dhaka, Bangladesh and Calverton, Maryland, USA: NIPORT, Mitra and Associates, and ICF International; 2016.

12. Bangladesh Bureau of Statistics. Preliminary report on household income and expenditure survey 2010. Statistics division, Ministry of Planning. Dhaka: The Government of the People's Republic of Bangladesh; 2011.

13. Food and Agriculture Organization of the United Nations (FAO), International Fund for Agricultural Development (IFAD), and W.F.P. (WFP). The State of Food Insecurity in the World 2012. Economic growth is necessary but not sufficient to accelerate reduction of hunger and malnutrition. Rome: FAO; 2012.
14. Grebmer, K.v., et al. Global Hunger Index: Armed Conflict and the Challenge of Hunger. 2015, International Food Policy Research Institute, and Concern Worldwide: Bonn, Washington, DC, and Dublin: Welthungerhilfe.2015.

15. Black RE, et al. Maternal and child undernutrition: global and regional exposures and health consequences. Lancet. 2008;371(9608):243-60.

16. Horton R. Maternal and child undernutrition: an urgent opportunity. Lancet. 2008;371(9608):179.

17. Helen Keller International (HJI) and James P. Grant School of Public Health (JPGSPH), State of food security and nutrition in Bangladesh. 2014: Dhaka. BD: HKI and JPGSPH; 2013.

18. Steel DG, McLaren CH. In search of a good rotation pattern. In: From Adam Smith to Michael Porter: Evolution of Competitiveness Theory. 2000. p. 309.

19. Helen Keller International (HKI), James P. State of Food Security and Nutrition in Bangladesh 2014. Bangladesh: Grant School of Public Health (JPGSPH); 2016.

20. Diaz-Bonilla E, Robinson S. Shaping globalization for poverty alleviation and food security. Washington, DC: International Food Policy Research Institute (IFPRI); 2001.

21. Coates J, Swindale A, Bilinsky P. Household Food Insecurity Access Scale (HFIAS) for measurement of food access: indicator guide. Washington, DC: Food and Nutrition Technical Assistance Project, Academy for Educational Development; 2007.

22. Moser C, Felton A. The Construction of an Asset Index Measuring Asset Accumulation in Ecuador. Chronic Poverty Research Centre Working Paper No. 87. 2007. Available at SSRN: https://ssrn.com/abstract=1646417.

23. Bursac $Z$, et al. Purposeful selection of variables in logistic regression. Source Code Biol Med. 2008;3:17.

24. Kersey M, Geppert J, Cutts DB. Hunger in young children of Mexican immigrant families. Public Health Nutr. 2007;10(04):390-5.

25. Usfar AA, Fahmida U, Februhartanty J. Household food security status measured by the USHousehold Food Security/Hunger Survey Module (USFSSM) is in line with coping strategy indicators found in urban and rural Indonesia. Asia Pac J Clin Nutr. 2007;16(2):368-74.

26. Mondal MH. Crop agriculture of Bangladesh: Challenges and opportunities. Bangladesh J Agric Res. 2010;35(2):235-45.

27. Regassa N, Stoecker BJ. Household food insecurity and hunger among households in Sidama district, southern Ethiopia. Public Health Nutr. 2012; 15(07):1276-83.

28. Mishra VK, Retherford RD. Women's education can improve child nutrition in India. 2000.

29. Thomas D, Strauss J, Henriques MH. How does mother's education affect child height? J Hum Resour. 1991;26:183-211.

30. Pitt MM, Khandker SR, Cartwright J. Empowering women with micro finance: Evidence from Bangladesh. Econ Dev Cult Chang. 2006;54(4):791-831.

31. Dewey KG, Cohen RJ. Does birth spacing affect maternal or child nutritional status? A systematic literature review. Matern Child Nutr. 2007;3(3):151-73.

32. Akmam W. Women's education and fertility rates in developing countries, with special reference to Bangladesh. Eubios Journal of Asian and International Bioethics. 2002;12(4):138-43.

33. Thorne-Lyman AL, et al. Household dietary diversity and food expenditures are closely linked in rural Bangladesh, increasing the risk of malnutrition due to the financial crisis. J Nutr. 2010;140(1):182S-8S.

34. Feleke ST, Kilmer RL, Gladwin CH. Determinants of food security in Southern Ethiopia at the household level. Agric Econ. 2005;33(3):351-63.

35. Chinnakali $P$, et al. Prevalence of household-level food insecurity and its determinants in an urban resettlement colony in north India. J Health Popul Nutr. 2014;32(2):227.

36. Shamsuddoha M, Chowdhury RK. Climate change impact and disaster vulnerabilities in the coastal areas of Bangladesh. Dhaka: COAST Trust; 2007.

37. Ziaei S, Naved RT, Ekstrom EC. Women's exposure to intimate partner violence and child malnutrition: findings from demographic and health surveys in Bangladesh. Matern Child Nutr. 2014;10(3):347-59.

38. Food and Agriculture Organization of the United Nations (FAO), International Fund for Agricultural Development (IFAD), and W.F.P. (WFP), The State of Food Insecurity in the World 2015. Meeting the 2015 international hunger targets: taking stock of uneven progress. Rome: FAO; 2015.

39. International Labour Office, Global Employment Trends 2012. Geneva: 2012.

40. Kyaw D. Rural Household's Food Security Status and Coping: Strategies to Food Insecurity in Myanmar. Institute of Developing Economies, Japan External Trade Organization; 2009. 